\title{
THE IMPACT OF INTRODUCING FITNESS THEMES IN THE PHYSICAL EDUCATION LESSON ON ADOLESCENT GIRLS
}

\author{
Ștefan TÜDÖS ${ }^{1}$, Ștefan Dragoș TOADER ${ }^{1}$, Nicoleta LEONTE ${ }^{2}$, \\ Ștefan Dănuț TUDORANCEA ${ }^{3 *}$ \\ ${ }^{1}$ National University of Physical Education and Sport, Faculty of Physical Education and Sport, Bucharest, \\ Romania \\ ${ }^{2}$ Politehnica University, Department of Physical Education and Sports-Kinetotherapy, Bucharest, Romania \\ 3 "Grigore Moisil" National College, Bucharest, Romania \\ *Corresponding author: stefantudor35@yahoo.com
}

https://doi.org/10.35189/dpeskj.2020.59.3.5

\begin{abstract}
The influence of physical development on adolescent girls place physical education and sport at the core of functional somatic and motor harmonisation, but also turns them into defining factors for a healthy lifestyle. Our research aims to find solutions for one of the desiderata of physical education, namely developing bio-psychomotor skills and building the ability to act and maintain a positive psychophysical tone in adolescent girls. In this regard, motor programmes were developed using the means of fitness, which were introduced in the physical education lesson. The research was carried out in the 2019-2020 school year at the "Grigore Moisil" National College in Bucharest. The groups participating in the experiment are made up of 40 girl students in the 10th grade (aged 15-16 years). The study was conducted over 8 weeks during 16 physical education lessons. The research subjects were assessed by initial and final tests. Following the motor programme performed using the means of fitness, the motor ability of the experimental group has improved, which is supported by significant statistical evidence for all 6 tests: push-ups, sit-ups, trunk extension from the prone position, standing long jump, 50-m speed run with a standing start, 800-m endurance run. The training programme applied to the experimental group had higher efficiency than the traditional training programme commonly used in the physical education lesson.
\end{abstract}

Keywords: physical education, fitness, tests, adolescent girls.

\section{Introduction}

Physical exercise is one of the most effective ways of intervention for psychophysical development in adolescence due to its major health and psychological benefits (Fedewa \& Ahn, 2011). Physical exercise has physical, biological effects (improved muscle and joint ability, cardiopulmonary capacity, etc.), but also psychological effects (improved perceptualmotor behaviour, attention, verbal, nonverbal and paraverbal communication ability, ideomotor skills, body schema, self-image, cognitive behaviour, social integration, etc.) (Phillips et al., 2017).

As a structure-generator, physical exercise plays a role in organizing motor responses and developing psychomotor behaviour, as well as a means of acquiring motor components included in the instrumental pattern necessary for operational constructs in other types of behaviour: cognitive, verbal, self-service and socialisation (Horghidan, 2000), and all of this is reflected in the harmonious development of personality (Balsalobre et al., 2014).

Research in the field certifies the importance of physical education in reducing physical inactivity during the childhood-adolescence transition, inspiring children to adopt the habit of 
performing independent physical activity throughout life (Vazou et al., 2019; Ivashchenko \& Kapkan, 2016).

Most studies and research on adolescent attitudes towards physical activity have so far been conducted in the school environment. Each intervention was designed to increase participation in physical activity and reduce sedentary lifestyle, risk factors and obesity. The school environment and extracurricular sports activity are the most suitable means for implementing the intervention because school is an efficient establishment for the promotion and development of physical exercise programmes involving a large number of children and adolescents. Students who do not want to participate in such a joint programme can perform it independently in their free time, at home. (Leonte \& Popescu, 2019; Culp, 1998)

These physical activity programmes facilitate the acquisition of skills and knowledge necessary to maintain a healthy lifestyle. Studies highlight that such programmes have increased participation in sports activities, improved the level of knowledge about a healthy lifestyle and contributed to changing attitudes towards the practice of physical exercise (McNamee et al., 2017; McKenzie et al., 1995).

Fitness is a trendy activity, which is why it has become fashionable for today's young people to go to the gym in order to practice this type of movement; all health gyms and clubs provide both the necessary equipment and trainers specialised in coordinating the activity.

Due to its rich content and the multitude of means that underpin this sports discipline, we can say that practicing fitness has a lot of advantages such as:

- favouring growth processes and optimising physical development, therefore achieving age-matched indices and the proportionality between them;

- forming a proper body attitude;

- preventing and combating global and segmental poor attitudes;

- increasing muscle mass in all muscle groups;

- achieving and maintaining optimal body weight;

- educating body aesthetics and movement expressiveness;

- improving exercise capacity of the body. (Ciomag \& Dinciu, 2014)

Since fitness is a term assigned to a whole range of activities and states, the means by which it aims to achieve its objectives will be as appropriate as possible. We face a multitude of motor acts, exercises and structures of exercises whose end goal is to obtain the muchdesired wellbeing of the body. In fitness, both specific and associated means are used.

To stimulate the increase of functional and morphological indices, to develop the overall exercise capacity of the body and thus to ensure the energetic background for performance, additional training that uses means from various sports is also needed. If properly administered, this component of general training, which is called physical training, can become a facilitating factor for the improvement of recovery processes by alternating the exercise structure. The means used in fitness are taken over from athletics (running, various jumping structures, various throws), sports games, swimming, basic gymnastics. (Ciomag, 2008) 


\section{Premises}

A premise is the initial proposition of an inferred reasoning that is accepted as a true statement, not as an obvious truth (Gagea, 1999). Thus, we believe that the main ideas (premises) that should be retained in order to formulate the working hypotheses of this study are the following:

- to conduct this research, we have started from the idea that subjects are clinically healthy;

- we have also considered that the practice of non-competitive fitness by female adolescents can have beneficial effects on their bodies;

- in epistemological terms, the exercise capacity dimension must take into account ageand gender-related features, which is why the fitness programme matches the anatomical and functional characteristics of adolescent girls. (Laurson et al., 2008; Annesi et al., 2005)

Individual training, which must consider the profile (model) of each subject, incorporates the following aspects: biological features such as: physical development (robustness, height, weight), predominant motor skills (speed, strength, agility), type of central nervous system (power, balance, etc.), gender, age (Fairclough \& Stratton, 2006); psychological features: temperament, character, perceptual ability, moral and volitional qualities (Chen et al., 2017), team integration ability, aptitude or predilection.

\section{Research purpose}

The purpose of this paper is to identify some aspects and ways of designing fitness programmes and then introduce them in physical education lessons so as to obtain positive effects on functional and motor parameters.

\section{Framework objectives}

A. Maintaining and improving health;

B. Enhancing fitness by:

- improving basic and utilitarian motor skills;

- increasing functional capacity, ensuring harmonious physical development, cultivating motor and psychomotor abilities;

C. Gaining a system of knowledge and skills specific to certain branches of sport (or bodily activities) to be practiced independently (during leisure);

D. Educating personality qualities or traits susceptible to be transferred into social activity (organisational ability, perseverance, responsibility for decision-making, team spirit, fairplay, respect for work, taking rational risk). 


\section{Research tasks}

- to determine the features of the two groups of adolescent girls in terms of age, physical condition, acquired fitness-specific motor skills and reactivity to specific effort;

- to investigate motor aspects by applying initial tests;

- to design training models for this category of subjects and distribute the weight of the means among the scheduled thematic components;

- to investigate motor changes induced by the proposed programmes using tests applied at the end of the training period;

- to identify differences between the two groups in terms of rate of progress, as well as its statistical significance.

\section{Research hypotheses}

The aforementioned premises and the findings derived from our practical experience have led us to formulate the following working hypotheses:

If the training process focused on introducing non-competitive fitness themes for female subjects is planned starting with the identification of individual needs and features, and the training programme is modelled accordingly, then physical fitness indicators will significantly change in the sense of reaching superior outcomes.

Introducing fitness themes that are found in the syllabus for the $10^{\text {th }}$ grade / 2 hours per week has effects on the physical, biological level, but also on improving muscle and joint ability, as well as cardiopulmonary capacity.

\section{Criteria and indicators to validate/invalidate the hypotheses}

The conditions to verify a hypothesis are of particular importance because this verification confirms or disproves that hypothesis.

In physical education and sport, one of the central problems of the experiment is to establish those variables whose manipulation accurately indicates the causal relationship formulated by the hypothesis. Thus, in our case, the independent variable is represented by the differently structured contents of the fitness-specific means, whose effects are expected and assessed. The dependent variable refers to a combination of effects - particular motor manifestations of the experimental group subjects. The experiment aims to establish the type of relationship between the variants of exercises and the effects assumed in the hypothesis.

If all elements that might influence the dependent variable are kept constant, one can estimate that the progress recorded in the experimental period is exclusively the effect of the independent variable.

The indicators used to validate the hypotheses involve the motor sphere: abdominal muscle strength, back muscle strength, arm muscle strength (push-ups), leg muscle strength (standing long jump), acceleration and movement speed (50-m speed run), cardiorespiratory (aerobic) endurance (800-m endurance run). 


\section{Methodology}

Research methods

In order to better know the complex issue of introducing fitness themes in physical education lessons, the following research methods were used:

- documentation - achieved through an assiduous search for the latest and most reliable sources of information (books, journals, syllabi, iconographic and computerized sources, etc.). The bibliographic study helped us to build the theoretical background, as well as the entire course of the current research, using databases such as Google Scholar, EBSCO, ProQuest and SpringerLink;

- pedagogical observation - consisted in the systematic monitoring of motor actions and activities and included:

a) the framework or setting where the research was conducted;

b) the content of the training activity;

c) the response attitude of the participants in the experiment.

- test method - aimed at gathering accurate information about motor features, based on which predictions were made. The results were assessed by statistical comparison with the results of the control group subjects in order to rank them in relation to the average success of the reference group.

The subjects were tested for:

- Explosive leg power: Standing long jump

Two attempts are allowed, and the best is retained; the jumping surface should be smooth and non-slippery; the results are recorded in meters and centimetres.

- Arm muscle strength: Flexion and extension in the elbow joint from the prone position, with support on the ground

From the prone position, with arms bent and palms against the ground at chest level, stretching and bending the arms; the number of repetitions is recorded.

- Abdominal muscle strength: Sit-ups

From the supine position, with palms behind the head, performing sit-ups; legs will be stretched and fixed to the ground; on raising, the trunk will be straight, with shoulders and elbows pulled backwards; the number of repetitions performed within 30 " is recorded.

- Back muscle strength: Trunk extension from the prone position

From the prone position on the gym mattress (with the torso outside the mattress), tilting the trunk forward to the ground and raising it with extension; legs are stretched, with support on the ground (fixed by the partner), and palms are held behind the head; elbows and shoulders are pulled backwards; the number of repetitions performed within 30 " is recorded.

- Travel speed: Speed run over the distance of 50-m flat, with a standing start

It is performed individually, with a standing start; the timer is started when the movement begins; two attempts are allowed, with a 10-minute break between 
repetitions; the best performance is retained; the results are recorded in seconds and tenths of a second.

- Aerobic endurance: Endurance run (800 m)

Materials required: sports field with flat surface, timer

Procedure: Subjects will be placed on a starting line drawn by the examiner and will perform an endurance run test; the results are recorded in minutes and seconds.

- statistical and mathematical method. In our research, the data obtained by measurements and tests were statistically processed, and the recorded indicators were the following: arithmetic mean, standard deviation, mean difference, coefficient of variation, independent t-test, standard error of difference.

\section{Subjects and site of study}

The research was conducted at the "Grigore Moisil" National College in Bucharest, in the 2019-2020 school year ( $1^{\text {st }}$ semester). The groups participating in the experiment are made up of 40 girl students in the $10^{\text {th }}$ grade (15 to 16 years old).

The type of sample is randomised, therefore based on the random selection technique. In psycho-pedagogical/methodological research studies where subjects cannot be selected without the risk of rendering incomplete the number of students in a classroom, the experiment and control groups are made up of subjects enrolled in parallel classrooms, considering that the "random" factor has also occurred at the initial formation of classrooms (Epuran, 2005).

The study was carried out over an 8-week period that represented the anatomical adaptation stage, being preceded and followed by the application of initial and final tests. The effort provided by the research subjects was consistent with the motor and morpho-functional features of adolescent girls (Table 1).

Table 1. Duration and stages of the experiment

\begin{tabular}{cl}
\hline \multicolumn{1}{c}{ Period } & \multicolumn{1}{c}{ Activity } \\
\hline $01.10 .2019-11.10 .2019$ & Initial test \\
$14.10 .2019-06.12 .2019$ & Implementation of the training programme \\
$09.12 .2019-20.12 .2019$ & Final test \\
\hline
\end{tabular}

\section{Experimental design}

This study is part of a comprehensive research on the development of autonomy in adolescent girls through fitness programmes introduced in physical education lessons; it falls into the category of comparative research conducted on two equivalent experimental groups, and the following variables were taken into account:

- CG (20 subjects) - represented the control group for which the value of the independent variable was "zero";

- EG (20 subjects) - represented the experimental group to which an independent variable (V), namely an operational system using the means of fitness was applied. 
The fitness-specific means and methods used in physical education lessons guided the entire methodology of applying the independent variable. The experimental group followed the fitness programme in the second part of the physical education lesson for 25 minutes, while the control group performed the usual training programme.

Physical education lessons had the following structure:

1. Warm-up (5-10 minutes)

2. Fundamental part (35 minutes)

T1 - Speed or Agility, or Motor Skills specific to sports branches and/or events (10 minutes)

T2 - Strength development in the main muscle groups through fitness-specific means (25 minutes)

3. Final part (2-5 minutes)

The way of addressing fitness programmes was structured so as to engage the segmental strength of the main muscle groups in the following order: lower body muscles, upper body muscles, arm muscles, abdominal muscles.

Increasing the efficiency of training through fitness programmes used in physical education lessons was related to the following aspects:

- The need to adapt and bring pre-university education as close as possible to the socioeconomic requirements of the current period. Today's youth should be fit, valid, trained to cope with the increasingly demanding requirements of everyday life;

- Physical education activity, meaning the practice of physical exercise within purposely designed structures, becomes a measure able to ensure health, but also the harmonious and aesthetic development of the body;

- Vigorous and regular practice of exercise develops the capacity for effort and work, and thus provides support for performing physical and mental effort during independent leisure motor activities or practising the professions for which students are being trained;

- Operational models (where structures are selected, ordered and quantified for a certain level of effort) lead to better time savings in relation to the activity type and structure;

- The use of simple, accessible, attractive and easy-to-perform means will quickly and efficiently engage female students in the proposed fitness programmes;

- New modern activities (such as fitness) become a permanent challenge among the daily activities of girl students and thus contribute to increasing the efficiency of physical exercise.

The characteristics of the anatomical adaptation stage are the following:

- at the beginning of the training programme, the 1RM test will be performed to clearly determine the initial level of motor skills (Faigenbaum et al., 2002);

- all muscles, tendons and ligaments should work so as to create a routine and balance between them, thus preventing the risk of injury;

- the activation of muscle groups will be performed during 2 physical education lessons per week, with a break of 1 day and 2 days, respectively;

- one exercise is performed for each muscle group, with a break of 60-90-120 seconds between two successive stations;

- it is recommended to avoid increasing the load too early.

Using the circuit method in the weight training lesson is advantageous due to the possibility of alternating the areas that need to be stimulated, thus facilitating faster recovery. 
Exercise intensity, when the circuit involves successive training of the lower body and upper body, is lower compared to unilateral activation, which leads to better load tolerance.

Muscle groups that must be first trained due to the upper or lower body characteristics will be engaged at the beginning of the lesson to ensure the initial adaptation to exercise.

Abdominal muscles are recommended to be engaged at the end of the circuit due to their role in stabilising the body, given that early fatigue increases the risk of injury.

The key to developing adapted fitness programmes is "individualisation". Thus, depending on the somatic type, namely the somatic features, the physical activity index and the speed of gaining muscle mass, adolescent girls will have different purposes: to tone or develop their muscle mass; to lose weight; to maintain optimal health.

Thus, individual needs and goals indicate the importance of developing adapted fitness programmes for adolescent girls.

The most effective method used to develop muscle strength indices in the physical education lesson is thought to be the circuit method. In this regard, structures of exercises grouped into circuits were developed. To give an example, we present Circuit no. 1:

Purpose: To increase general and segmental muscle indices

- 6-8-10 stations customised for each subject, according to the somatic type

- 30" exercise in weeks 1 and 2

- $\quad 40$ " exercise in week 3

- $\quad 40$ " exercise in week 4

- 45 " break between stations

The entire circuit is repeated:

- 2 times in weeks 1 and 2

- $\quad 3$ times in weeks 3 and 4

- Break between circuits: 2-3 minutes

- Pulse: 120-140 beats per minute

Working period: 4 weeks

Such an adapted fitness programme consists of 6-8-10 exercises that involve all muscle groups of the body. Operational training structures included the following means, which will not be successively targeted to the same muscle group.

The description of bodyweight exercises, dumbbell exercises and exercises on fitness plate machines, when the weight adjustment is done at a rate of $5 \mathrm{~kg}$

1. Calf extension on the thigh while sitting on the machine

2. Leg press to $45^{0}$ from the supine position with lower limbs obliquely up

3. Deep squats with dumbbells in both hands

4. Raising heels from standing with dumbbells in both hands

5. Pulley hip extension

6. Pulley abductions

7. Horizontal leg press

8. Butterflies from sitting on the Pec Deck machine

9. Side dumbbell lifts from the supine position on the gym bench

10. Sideways dumbbell lifts from the supine position on the gym bench

11. Dumbbell lifts from the supine position on the gym bench

12. Prone position with palm support: bending and stretching the arms (push-ups) 
13. Lat machine pulldowns by carrying the bar behind the head

14. Pulldowns with the top cable of the Lat machine by carrying the bar to the chest (elbows can be slightly bent)

15. Shoulder lifts and rotation from front to back with dumbbells in both hands

16. Vertical press with dumbbells from sitting

17. Side arm lifts with dumbbells from standing

18. Sideways arm lifts, the other holding the support for balance

19. Front lifts with dumbbells from sitting or standing, alternately or simultaneously, to shoulder level or above head

20. Forearm flexion on the arms with the lower cable of the Lat machine

21. Alternating forearm flexion on the arm with the dumbbell

22. Trunk flexion and extension from the prone position with hands behind the head on the tilted device bench

23. Trunk extension from the prone position with hands behind the head

24. Forearm extension on the arms with the top cable of the Lat machine

25. Standing with bent arms and elbows up, while holding dumbbells in both hands behind the head: stretching the arms up and return

26. Trunk lifts from the supine position on the tilted device bench

27. Raising the legs from the supine position on the horizontal bench (inverted crunch)

28. Trunk rotation with dumbbells in both hands

29. Trunk lifts from the supine position with palms behind the head and half-bent knees

The correlation between exercise parameters and the somatic type in the anatomical adaptation stage is highlighted in Table 2.

Table 2. Correlation between exercise parameters and the somatic type in the anatomical adaptation stage

\begin{tabular}{lccc}
\hline \multirow{2}{*}{ Exercise parameters } & \multicolumn{3}{c}{ Somatic type } \\
\cline { 2 - 4 } & Ectomorph & Mesomorph & Endomorph \\
\hline No. of repetitions & 6-10 repetitions & $12-15$ repetitions & $12-15$ repetitions \\
Sets & 3 sets & 3 sets & \\
Break between stations & 2 minutes (large) & $1-2$ minutes (small) & $1-2$ minutes (small) \\
Break between sets & 3 minutes & 3 minutes & 3 minutes \\
(circuits) & active break & active break & active break \\
Load & moderate (50\%-60\%) & varied (low-medium-high) & medium-high \\
Recommendations & - forced repetitions & - diversity of programmes & - aerobic effort \\
& - free weights & - forced repetitions & - free weights and \\
& - break - 1-3 free days & - aerobic effort & analytical machines \\
between lessons & - free weights and & - until exhaustion \\
& & analytical machines & - forced repetitions \\
& & - break - 1-3 free days & - variation of programmes \\
& & between lessons & - break - 1-3 free days \\
\end{tabular}

Circuit training is suitable for beginners because it develops both the general strength and cardiorespiratory capacity necessary to perform physical exercise. The variety of exercises used in adapted fitness programmes makes adolescent girls be attracted to this activity and thus the monotony of lessons is removed. 
The type of (multifunctional) fitness equipment and its placement in the sports hall of the "Grigore Moisil" National College in Bucharest requires the presence of several partners who can help when needed during the exercise.

\section{Results}

At the end of the experimental intervention based on the application of operational systems using the means of fitness as themes in physical education lessons, we wanted to know whether there were significant differences between the results of the two groups.

Table 3. Statistical values obtained in motor tests (control/experimental groups) - Initial test

\begin{tabular}{|c|c|c|c|c|c|c|c|c|c|c|c|c|}
\hline & \multicolumn{2}{|c|}{ Push-ups } & \multicolumn{2}{|c|}{ Sit-ups } & \multicolumn{2}{|c|}{$\begin{array}{c}\text { Trunk } \\
\text { extension }\end{array}$} & \multicolumn{2}{|c|}{$\begin{array}{l}\text { Standing long } \\
\text { jump }\end{array}$} & \multicolumn{2}{|c|}{ 50-m speed run } & \multicolumn{2}{|c|}{$\begin{array}{c}800-\mathrm{m} \text { endurance } \\
\text { run }\end{array}$} \\
\hline & CG & EG & CG & EG & CG & EG & $\mathrm{CG}$ & EG & CG & EG & $\mathrm{CG}$ & EG \\
\hline Mean & 3.10 & 3.75 & 16.10 & 15.85 & 25.40 & 26.40 & 1.40 & 1.39 & 9.19 & 8.995 & 5.05 & 5.13 \\
\hline SD & 2.65 & 1.48 & 4.20 & 2.87 & 9.08 & 7.91 & 0.20 & 0.18 & 0.87 & 0.59 & 0.56 & 0.26 \\
\hline SEM & 0.59 & 0.33 & 0.94 & 0.64 & 2.03 & 1.77 & 0.04 & 0.04 & 0.19 & 0.134 & 0.12 & 0.06 \\
\hline SED & \multicolumn{2}{|c|}{0.68} & \multicolumn{2}{|c|}{1.138} & \multicolumn{2}{|c|}{2.692} & \multicolumn{2}{|c|}{0.061} & \multicolumn{2}{|c|}{0.237} & \multicolumn{2}{|c|}{0.139} \\
\hline Student's & \multicolumn{2}{|c|}{$\mathrm{p}=0.3450$} & \multicolumn{2}{|c|}{$\mathrm{p}=0.8273$} & \multicolumn{2}{|c|}{$\mathrm{p}=0.7123$} & \multicolumn{2}{|c|}{$\mathrm{p}=0.8707$} & \multicolumn{2}{|c|}{$\mathrm{p}=0.4162$} & \multicolumn{2}{|c|}{$\mathrm{p}=0.557$} \\
\hline t-test & \multicolumn{2}{|c|}{$\mathrm{t}=0.9563$} & \multicolumn{2}{|c|}{$\mathrm{t}=0.2196$} & \multicolumn{2}{|c|}{$\mathrm{t}=0.3715$} & \multicolumn{2}{|c|}{$\mathrm{t}=0.1638$} & \multicolumn{2}{|c|}{$\mathrm{t}=0.8220$} & \multicolumn{2}{|c|}{$t=0.5926$} \\
\hline
\end{tabular}

The data obtained from the assessment were statistically processed using the following statistical indicators: arithmetic mean, standard deviation (SD) and coefficient of variation $(\mathrm{CV})$. To verify the significance of mean differences, the independent t-test was applied (between the two groups), the significance threshold being established, in our case, for $\mathrm{N}=$ 20 at a p-value $<0.05$. The statistical values mentioned above were calculated using the GraphPad program. (Table 3, Figure 1)

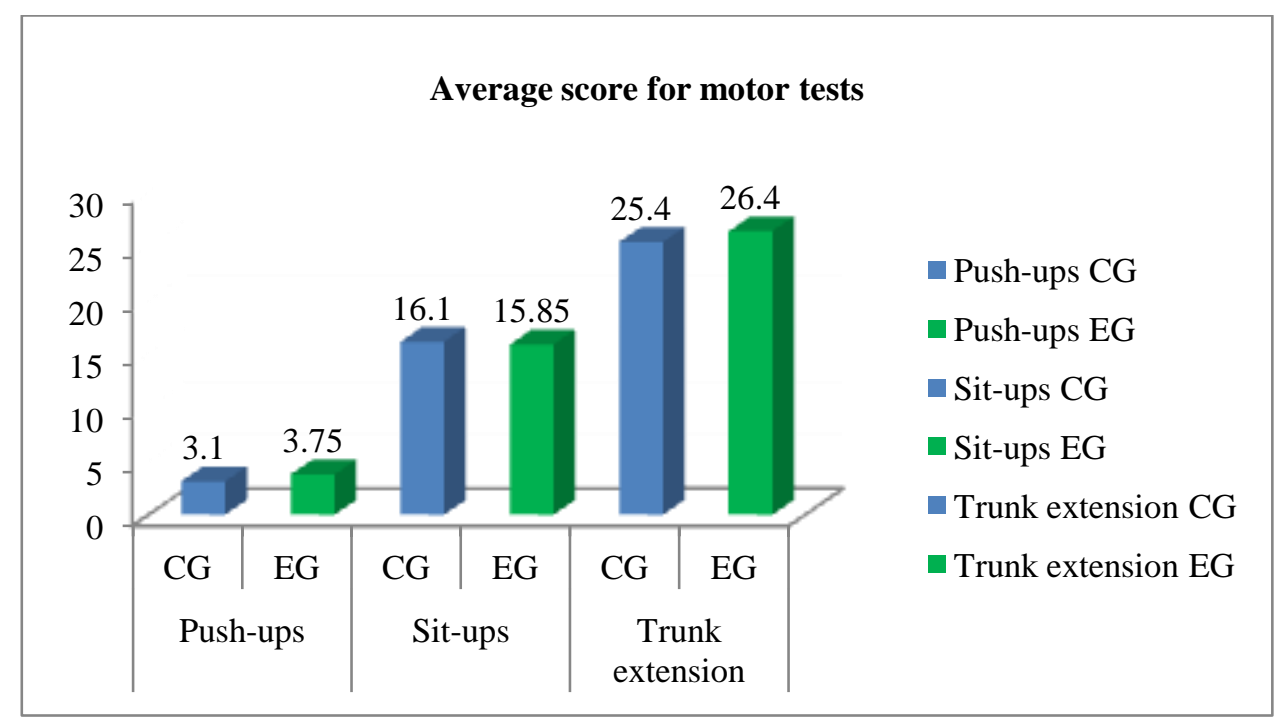

Figure 1. Average score for motor tests - Initial testing (number of repetitions) 
In the initial test, measurements for the following motor indicators: flexion and extension of the elbow joint from the prone position (push-ups), vertical trunk lifts from the supine position (sit-ups), trunk extension from the prone position, standing long jump, 50-m speed run with a standing start and 800-m endurance run were performed on 20 control group subjects and 20 experimental group subjects.

The arithmetic means obtained by the two groups in the initial test were not significantly different $(\mathrm{p}>0.05)$, the values being close to each other in all motor tests. The sample is relatively homogeneous in the initial test.

Table 4. Progress of the experimental group - Final test

\begin{tabular}{|c|c|c|c|c|c|c|c|c|c|c|c|c|}
\hline & \multicolumn{2}{|c|}{ Push-ups } & \multicolumn{2}{|c|}{ Sit-ups } & \multicolumn{2}{|c|}{$\begin{array}{c}\text { Trunk } \\
\text { extension }\end{array}$} & \multicolumn{2}{|c|}{$\begin{array}{c}\text { Standing long } \\
\text { jump }\end{array}$} & \multicolumn{2}{|c|}{$\begin{array}{c}50-\mathrm{m} \text { speed } \\
\text { run }\end{array}$} & \multicolumn{2}{|c|}{$\begin{array}{c}800-\mathrm{m} \\
\text { endurance run }\end{array}$} \\
\hline & CG & EG & CG & EG & CG & EG & CG & EG & CG & EG & CG & EG \\
\hline Mean & 2.80 & 8.35 & 14.95 & 22.05 & 21.55 & 27.40 & 1.39 & 1.61 & 9.25 & 8.48 & 5.16 & 4.90 \\
\hline $\mathrm{SD}$ & 2.26 & 1.35 & 3.85 & 4.47 & 7.14 & 6.79 & 0.18 & 0.15 & 0.817 & 0.59 & 0.20 & 0.25 \\
\hline SEM & 0.51 & 0.30 & 0.86 & 1.00 & 6.79 & 1.52 & 0.04 & 0.03 & 0.183 & 0.13 & 0.04 & 0.05 \\
\hline SED & \multicolumn{2}{|c|}{0.589} & \multicolumn{2}{|c|}{1.318} & \multicolumn{2}{|c|}{2.203} & \multicolumn{2}{|c|}{0.054} & \multicolumn{2}{|c|}{0.226} & \multicolumn{2}{|c|}{0.073} \\
\hline Student's & \multicolumn{2}{|c|}{$\mathrm{p}=0.0001$} & \multicolumn{2}{|c|}{$\mathrm{p}=0.0001$} & \multicolumn{2}{|c|}{$p=0.0115$} & \multicolumn{2}{|c|}{$\mathrm{p}=0.002$} & \multicolumn{2}{|c|}{$\mathrm{p}=0.0016$} & \multicolumn{2}{|c|}{$\mathrm{p}=0.008$} \\
\hline t-test & \multicolumn{2}{|c|}{$t=9.4256$} & \multicolumn{2}{|c|}{$\mathrm{t}=5.3878$} & \multicolumn{2}{|c|}{$t=2.6558$} & \multicolumn{2}{|c|}{$\mathrm{t}=4.1150$} & \multicolumn{2}{|c|}{$\mathrm{t}=3.3896$} & \multicolumn{2}{|c|}{$t=3.6289$} \\
\hline
\end{tabular}

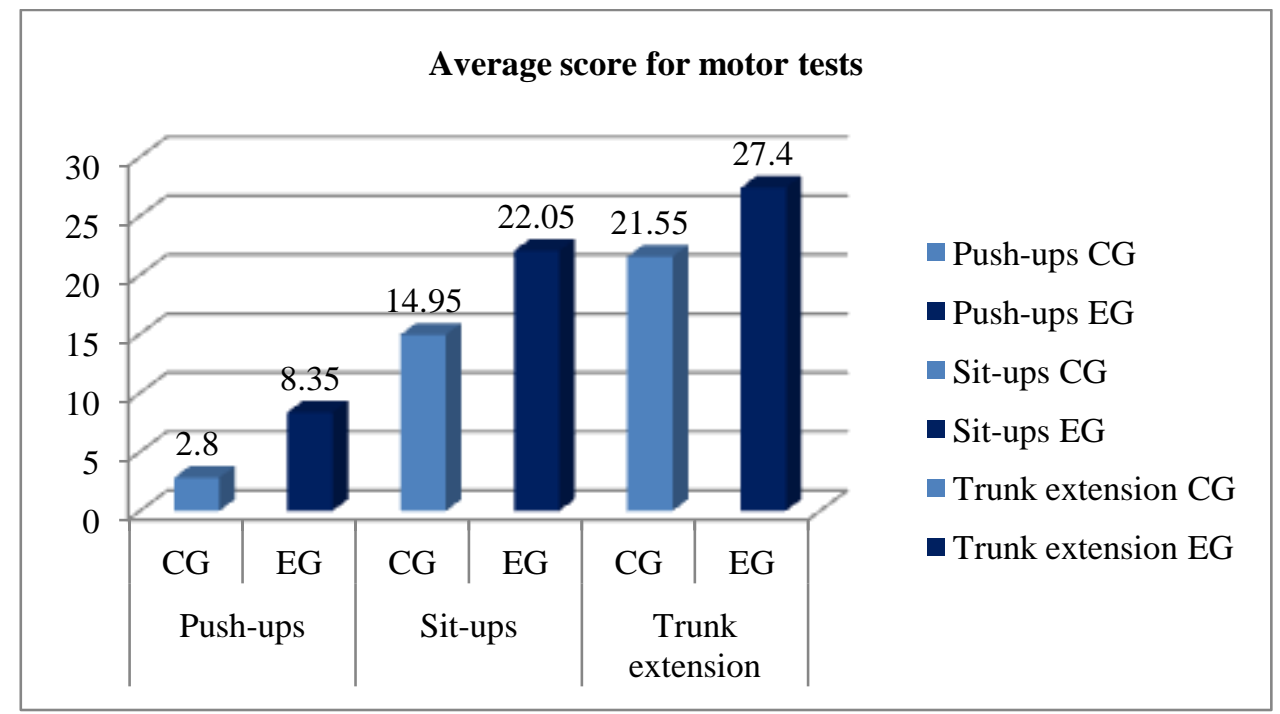

Figure 2. Average score for motor tests - Final testing (number of repetitions)

For the push-up test, the average increased by 4.6 repetitions, from 3.75 in initial testing to 8.35 repetitions in final testing. Data dispersion kept its homogeneous structure in the final test too. After verifying the statistical hypothesis with the t-test, it resulted that the $95 \%$ confidence interval ranged between $(1.12,2.51)$, and the mean difference was statistically significant at $\mathrm{p}<0.05$.

For the sit-up test, the score increased by 6.2 repetitions on average after the training period, from 15.85 to 22.05 repetitions. Data dispersion kept its homogeneous structure in the final test too. After verifying the statistical hypothesis with the t-test, it resulted that the mean 
difference reached the statistical significance threshold at $\mathrm{p}<0.05$, the difference between the two groups being statistically significant $(\mathrm{p}=0.0001)$.

The average score for vertical trunk lifts (trunk extension) increased by 1 repetition, from 26.4 repetitions in the initial test to 27.4 in the final test. After verifying the statistical hypothesis with the $\mathrm{t}$-test, it resulted that the mean difference was statistically significant at $\mathrm{p}$ $<0.05$, the $95 \%$ confidence interval ranging between $(2.26,2.89)$.

For the standing long jump, the average score in the final test is $0.22 \mathrm{~cm}$ higher than in the initial test, the means being $1.39 \mathrm{~m}$ and $1.61 \mathrm{~m}$, respectively. Data dispersion kept its homogeneous structure in the final test too. Verification of the statistical hypothesis with the $\mathrm{t}$-test has led to the conclusion that the mean difference is statistically significant at $\mathrm{p}=0.002$.

For the 50-m speed run, it has been found that the average time recorded in the final test is shorter by 0.51 seconds compared to the initial test, the means being 8.99 seconds and 8.48 seconds, respectively. Data dispersion kept its homogeneous structure in the final test too. When verifying the statistical hypothesis with the t-test, it has been noted that the mean difference is statistically significant at $\mathrm{p}<0.01$.

\section{Conclusion}

The experimental approach aimed to develop motor skills in adolescent girls through fitness-specific programmes has highlighted that physical education lessons where fitness is the sports discipline used to achieve the objectives of the lesson are more attractive and especially much more efficient to further develop the motor ability of female adolescents included in the study.

Fitness develops motor skills in adolescent girls and provides the opportunity to adapt its specific means to various environmental situations. Health-related fitness characterises the level of adaptation to the demands of professional and social life as an attribute of the quality of life. Functional fitness relies on a healthy body (especially the lungs, heart, bone-joint and muscle systems). The functionality of these systems and organs are good indicators of general physical fitness.

Reaching optimal fitness involves respecting the principle of individualisation, which is practically achieved in two main directions: general training and specialised training.

The application of experimental tests allows us to state that fitness, through its means, contributes to the development of motor skills, providing models of social training and sociomotricity.

Continuing motor education in adolescent girls enables to form life patterns that result in achieving better socialisation, combating sedentary lifestyles, overeating, smoking and alcohol consumption, using free time for one's body, thus leading to increased quality of life.

\section{Authors' Contributions}

All authors have equally contributed to this study and should be considered as main authors. 


\section{References}

Annesi, J. J., Westcott, W. L., Faigenbaum, A. D., \& Unruh, J. L. (2005). Effects of a 12week physical activity protocol delivered by YMCA after-school counselors (Youth Fit for Life) on fitness and self-efficacy changes in 5-12-year-old boys and girls. Research Quarterly for Exercise and Sport, 76(4), 468-476. https://doi.org/10.1080/02701367.2005.10599320

Balsalobre, F. J. B., Sánchez, G. F. L., \& Suárez, A. D. (2014). Relationships between physical fitness and physical self-concept in Spanish adolescents. Procedia - Social and Behavioral Sciences, 132, 343-350. https://doi.org/10.1016/j.sbspro.2014.04.320

Chen, W., Hammond-Bennett, A., Hypnar, A., \& Mason, S. (2018). Health-related physical fitness and physical activity in elementary school students. BMC Public Health, 18(1): 195. https://doi.org/10.1186/s12889-018-5107-4

Ciomag, R. V. (2008). Fitnessul ieri, azi și întotdeauna [Fitness yesterday, today and always]. ASE.

Ciomag, V., \& Dinciu, C. (2014). The fitness in physical education class - A determinant promoter for student's health and body esthetic. Marathon, 6(2), 130-135. https://www.ase.ro/marathon/revista/pdf/vol6/vol2/2\%20CIOMAG\%20VALENTINA.pdf

Culp, R. H. (1998). Adolescent girls and outdoor recreation: A case study examining constraints and effective programming. Journal of Leisure Research, 30(3), 356-379. https://doi.org/10.1080/00222216.1998.11949838

Epuran, M. (2005). Metodologia cercetării activităților corporale [Research methodology for bodily activities]. FEST.

Faigenbaum, A. D., Milliken, L. A., LaRosa Loud, R., Burak, B. T., Doherty, C. L., \& Westcott, W. L. (2002). Comparison of 1 and 2 days per week of strength training in children. Research Quarterly for Exercise and Sport, 73(4), 416-424. https://doi.org/10.1080/02701367.2002.10609041

Fairclough, S., \& Stratton, G. (2006). Physical activity, fitness, and affective responses of normal-weight and overweight adolescents during physical education. Pediatric Exercise Science, 18(1), 53-63. https://doi.org/10.1123/pes.18.1.53

Fedewa, A. L., \& Ahn, S. (2011). The effects of physical activity and physical fitness on children's achievement and cognitive outcomes: A meta-analysis. Research Quarterly for Exercise and Sport, 82(3), 521-535. https://doi.org/10.1080/02701367.2011.10599785

Gagea, A. (1999). Metodologia cercetării științifice în educație fizică și sport [Scientific research methodology in physical education and sport]. Editura Fundației România de Mâine.

Horghidan, V. (2000). Problematica psihomotricității [Psychomotricity issues]. Globus.

Ivashchenko, O. V., \& Kapkan, O. O. (2016). Informative pedagogic control indicators of 1415 years age girls' motor fitness. Pedagogics, Psychology, Medical-Biological Problems of Physical Training and Sports, 20(6), 18-25. https://doi.org/10.15561/18189172.2016.0603

Laurson, K. R., Brown, D. D., Dennis, K. K., \& Cullen, R. W. (2008). Heart rates of high school physical education students during team sports, individual sports, and fitness activities. Research Quarterly for Exercise and Sport, 79(1), 85-91. https://doi.org/10.1080/02701367.2008.10599463

Leonte, N., \& Popescu, O. (2019). Persuasion - A means of the attitudinal change in the practice of sports activity for students in technical education. Gymnasium, 19(1), 96-110. DOI: 10.29081/gsjesh.2018.19.1.09

McKenzie, T. L., Feldman, H., Woods, S. E., Romero, K. A., Dahlstrom, V., Stone, E. J., Strikmiller, P. K., Williston, J., M., \& Harsha, D. W. (1995). Children's activity levels and 
lesson context during third-grade physical education. Research Quarterly for Exercise and Sport, 66(3), 184-193. https://doi.org/10.1080/02701367.1995.10608832

McNamee, J., Timken, G. L., Coste, S. C., Tompkins, T. L., \& Peterson, J. (2017). Adolescent girls' physical activity, fitness and psychological well-being during a health club physical education approach. European Physical Education Review, 23(4), 517-533. https://doi.org/10.1177/1356336X16658882

Phillips, S. R., Marttinen, R., \& Mercier, K. (2017). Fitness assessment: Recommendations for an enjoyable student experience. Strategies, 30(5), 19-24. https://doi.org/10.1080/08924562.2017.1344168

Vazou, S., Mischo, A., Ladwig, M. A., Ekkekakis, P., \& Welk, G. (2019). Psychologically informed physical fitness practice in schools: A field experiment. Psychology of Sport and Exercise, 40, 143-151. https://doi.org/10.1016/j.psychsport.2018.10.008 